\title{
The epidemiology of uveal melanoma in Germany: a nationwide report of incidence and survival between 2009 and 2015
}

\author{
Ahmad Samir Alfaar, (D) Anas Saad ${ }^{3}$ (D) $\cdot$ Peter Wiedemann $^{1} \cdot$ Matus Rehak $^{1}$ \\ Received: 12 December 2020 / Revised: 2 July 2021 / Accepted: 3 July 2021 / Published online: 4 October 2021 \\ (c) The Author(s) 2021
}

\begin{abstract}
Purpose To calculate the overall incidence of uveal melanoma in Germany and to compare incidences in different German states. In addition, we computed the overall and cancer-specific survival rates nationwide.

Methods Incidence data for the period between 2009 and 2015, covering the entire German population, was collected through the German Center for Cancer Registry. ICD-O-3 topography codes C69.3-C69.4 and histology codes for melanoma subtypes were used to collect the incidence data. Confidence Intervals with a level of 95\% (95\% CI) were calculated for rates. Survival was calculated using the Kaplan-Meier. The log-rank test was used for survival comparisons.

Results This study comprised 3654 patients with uveal melanomas, including 467 (12.8\%) with iridial and ciliary body tumors. The overall age-standardized incidence rate (ASIR) was 6.41 person per million. Generally, the ASIR was higher in males than females (6.67 (95\% CI 6.37-6.98) vs. 6.16 (95\% CI 5.88-6.45 per million). Higher crude incidence rates were noted in the northeastern states (12.5 per million (95\% CI 10.5-14.7) in Mecklenburg-Vorpommern) compared with the southwestern states (2.1 per million (95\% CI 1.7-2.6) in Hessen). The 5-year overall survival stood at 47\%, while the cancer-specific survival stood at $84 \%$. Multivariate analysis showed that women, younger patients, and patients living in Berlin achieved significantly higher overall survival.

Conclusion Overall ASIR of uveal melanoma in Germany indicates that the disease is more common in males and that it follows the same geographical distribution previously noted in central European countries, with the highest incidence in northern parts of Germany.
\end{abstract}

\section{Key messages}

- The overall age-adjusted incidence of uveal melanoma in Germany between 2009 and 2015 is 6.41 per million

- Choroid was the most common site of uveal melanoma. Men showed a higher incidence than women.

- The incidence of uveal melanoma in Germany stands at a figure between those of northern and southern European countries. This corroborates the theory of higher incidences of uveal melanoma the higher the latitude in Europe.

- The five-Year cumulative overall survival rate was $47 \%$, compared with an $84 \%$ cancer-specific survival rate.

Keywords Melanoma $\cdot$ Uvea $\cdot$ Ciliary body $\cdot$ Choroid; incidence $\cdot$ Germany

\section{Introduction}

Ahmad Samir Alfaar

ahmed@alfaar.de; ahmed.alfaar@charite.de

Extended author information available on the last page of the article
Uveal melanoma is the most common adulthood primary ocular malignancy [1]. It most frequently arises from the choroid and less commonly from the ciliary body and iris. In the USA, the age-standardized incidence was estimated 
at 5.1 per million, a figure that remained constant over the years [2]. The disease rarely affects children [3]. The incidence increases with age and plateaus or declines after the age of $75[2,4]$. Previous studies have shown a relation between incidence and era of birth, gender, ethnicity, and geographical location. White population and males were shown to have higher incidences of the disease [5]. Higher latitudes were associated with increased incidence of uveal melanoma in the USA [6]. A study conducted between 1983 and 1994 reported similar latitude-associated differences in the incidence of uveal melanoma, with incidences of 2 per million in southern Europe, compared with more than 8 per million in northern countries [4]. This study, however, examined data from only one German state, Saarland, which represents only $1 \%$ of the German population. Saarland is located on the very southwest borders with France and belonged to the previous West Germany, which had a different healthcare system than that of East Germany prior to unification in 1990 [7, 8]. Therefore, we expected to find a disparity in incidences of uveal melanoma and treatment outcomes between eastern and western states, including Saarland. We aimed at determining the crude and age-standardized incidence rates of uveal melanoma in Germany at the national level between 2009 and 2015. We further aimed to investigate disease characteristics and treatment outcomes including the nationwide overall and cancer-specific survival rates of uveal melanoma patients.

\section{Methods}

\section{Study population and methods}

Data from 2009 to 2015, covering the entire population of Germany, were gathered from the German population-based cancer registries through the German Center for Cancer Registry at the Robert Koch Institute together with the Association of Population Cancer Registries in Germany (GEKID) [9]. Data collected pertained to patients 15 years of age or older. Further details on the methodologies of the German Cancer Registry are available elsewhere [10].

Patients were identified as having uveal melanoma by using the ICD-O-3 topography codes, including choroid (ICD-O-3 topography code C69.3), the ciliary body (and iridial) code (C69.4), and histology codes for melanoma and malignant behavior codes. Patients initially coded as suffering from retinal melanomas $(n=10)$ were recoded as having choroidal disease. This was done with the knowledge of previous practices where there was often miscoding of this group of patients [2]. We used the International Classification of Diseases version 10 for the purposes of coding causes of death. Cause-specific survival rates were determined by analyzing deaths caused by choroid, ciliary body, and retinal disease (C693, C694, and C692, respectively). We excluded patients with unknown or benign disease behavior as well as those whose diagnoses were reported on death certificates only (DCO) to ensure quality of the data collected. No patients were reported as having had uveal melanoma based on DCO in this cohort. The TNM classification version 7 was used to determine staging in $88.1 \%$ of the tumors, followed by version 6 in 11.4\%. Staging was determined in a minority of cases through the use of the TNM versions $8(n=13)$ or $5(n=4)$ [11]. For practical reasons, we have joined them together in the analysis.

Population estimates as well as the German Standard Population Report of the 2011 Census, both provided by the Federal Statistical Office, were used to calculate crude (CR) and age-standardized incidence rates (ASIR) [12]. We plotted the incidences of uveal melanomas in the federal states at annual intervals according to the annual population estimates provided by the Federal Statistical Office. For the purposes of this study, the German states of Schleswig-Holstein, Hamburg, Lower Saxony, Bremen, North Rhine-Westphalia, Berlin, Brandenburg, Mecklenburg-West Pomerania, and Saxony-Anhalt were grouped as northern states. Conversely, the states of Hesse, Rhineland-Palatinate, BadenWürttemberg, Bavaria, Saarland, Saxony, and Thuringia were grouped as southern states. In order to examine the burden of disease in the regions of the former East Germany, the states of Brandenburg, Sachsen, Thuringia, Mecklenburg-West Pomerania, and Saxony-Anhalt were grouped as eastern states. Data from the formerly divided Berlin was represented separately. Data for each group were then further subdivided by age and gender, and further analysis was conducted accordingly. Further information on data collection and analysis can be found elsewhere [13].

\section{Software and statistical analysis}

The IBM SPSS version 27 was used to conduct the descriptive statistical analysis [14]. Microsoft Excel for Office 365 was used to organize data and calculate incidence rates [15]. Tableau version 2020.1.2 was used to map the results on OpenStreetMaps and create incidence graphs [16]. Kaplan-Meier was used to calculate survival rates. The log-rank statistic was used to compare survival rates among different groups. A $p$-value of 0.05 or lower was considered significant for two-tailed tests. We calculated confidence intervals for $95 \%$ level $[17,18]$. Directly standardized rates were calculated using methods mentioned elsewhere [17]. Annual percent change (APC) was calculated using the JoinPoint Software version 4.9.0 and using permutation test for selecting the model [19]. We also conducted a multivariate Cox regression analyses using "survminer" version 0.4.9 and "survival" version 3.2-10 packages in R software version 4.0.4 (2021-02-15)— the R Foundation for Statistical 
Computing, to estimate the hazard ratios of the influence of age at diagnosis, sex, topography, and geographical location on overall and cancer-specific survival.

\section{Results}

\section{Patients' characteristics}

Of the 3654 uveal melanoma diagnoses reviewed in this study, 3187 (87.2\%) were choroidal melanomas (Table 1). Mean age at presentation was 65.41 (95\% CI: 64.98-65.84) years of age, while the median stood at 67.5 (range $=83.5$, interquartile range: 18.69 ) years. No significant differences in age of presentation were detected between men and women $(\mathrm{t}=-1.9, p$-value $=0.055)$ or patients with choroidal versus ciliary body tumors $(\mathrm{t}=-1.7, \mathrm{p}$-value $=0.8)$ (Fig. 1, Supplementary Table 1). The overall age-standardized incidence of uveal melanoma was 6.41 per million (95\% CI 6.21-6.62). The incidence of uveal melanoma was higher among men than women (6.67 (95\% CI 6.37-6.98) vs. 6.16 (95\% CI 5.88-6.45) per million). Northern states had higher crude incidence rates compared with southern states (7.65 (95\% CI 7.33-7.97) vs 5.21 (95\% CI 4.95-5.48) (Fig. 2, Supplementary Table 5). Mecklenburg-Vorpommern, a northern state, had the highest crude incidence rate among all German states (12.5 per million; 95\% CI 10.5-14.7), while Hessen, a south-central state, had the lowest incidence rate (2.1 per million; 95\% CI 1.7-2.6). Overall, incidences of uveal melanoma were higher in males than females (Fig. 1). The ASIR in males reached a peak of 1.32 per million in the 70-74 age group and in females in the same age group with ASIR of 1.1 per million. Of all patients, $55.7 \%$ were diagnosed at the $\geq 65$ years of age, while only $7.5 \%$ were diagnosed at 15-45 years of age. The ASIR fluctuated over the years, reaching a peak in 2010 of 7.8 per million, and ended in a trough in 2015 at 5.2 per million. The overall trend showed a slight decreasing incidence with APC of -2.8 (95\% CI-9.6-4.5, p-value $=0.359$ ) (Fig. 1B). The details of the incidence are presented in Supplementary Tables 2, 3, 4, and 5.

\section{Tumor characteristics}

Histological confirmation was reported for $79.2 \%$ of patients; diagnosis was determined solely clinically in another $19.4 \%(n=709)$. Postoperative histopathological prefixes for TNM were added for $14 \%$ of patients $(n=541)$. TNM T was reported in $45 \%$ of all patients $(n=1252)$, including $9.7 \%(n=354)$ as TNM Tx. Out of all patients reported with TNM T1-4, patients with T3 stood at $32.2 \%$ $(n=403)$, followed those with T2 $(28.5 \%, n=357)$ (Table 2). Further histological features are detailed in Table 2 and Supplementary Table 6. Ninety-eight tumors showed histological features of differentiation, including 74 (75.5\%) well-differentiated tumors. Most of the tumors were reported as malignant histological subgroup NOS (Non-Otherwise Specified) melanomas $(n=3216,88 \%)$, followed by spindle cell-NOS melanomas $(5.4 \%, \mathrm{n}=197)$.

\section{Therapy}

Records reported details of patient treatment for 253 (6.9\%) patients. Of these, 79 (31.2\%) only received radiation therapy, 60 (23.7\%) underwent operations, and 39 (15.4\%) were treated with both irradiation and a surgical intervention (Supplementary Table 7).

Table 1 Patients Characteristics

\begin{tabular}{|c|c|c|c|c|c|c|c|c|c|c|c|c|c|c|c|c|c|}
\hline & & \multicolumn{8}{|c|}{ Topography } & \multicolumn{8}{|c|}{ Sex } \\
\hline & & \multicolumn{3}{|c|}{ C693 - Choroid } & \multicolumn{3}{|c|}{ C694 - Ciliary body } & \multicolumn{2}{|c|}{ Total } & \multicolumn{3}{|c|}{ male } & \multicolumn{3}{|c|}{ female } & \multicolumn{2}{|c|}{ Total } \\
\hline & & $\mathrm{N}$ & $\begin{array}{c}\text { Row } N \\
\%\end{array}$ & $\underset{\%}{\mathrm{Col} N}$ & $\mathrm{~N}$ & $\begin{array}{c}\text { Row N } \\
\%\end{array}$ & Col N \% & $\mathrm{N}$ & Col N \% & $\mathrm{N}$ & $\begin{array}{c}\text { Row N } \\
\%\end{array}$ & Col N \% & $\mathrm{N}$ & $\begin{array}{c}\text { Row } N \\
\%\end{array}$ & Col N \% & $\mathrm{N}$ & Col N \% \\
\hline \multirow{6}{*}{ 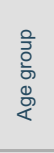 } & $15-29$ & $32 a$ & $97.0 \%$ & $1.0 \%$ & $1_{a}$ & $3.0 \%$ & $0.2 \%$ & 33 & $0.9 \%$ & $18 \mathrm{a}$ & $54.5 \%$ & $1.0 \%$ & $15 a$ & $45.5 \%$ & $0.8 \%$ & 33 & $0.9 \%$ \\
\hline & $31-44$ & $212 \mathrm{a}$ & $88.0 \%$ & $6.7 \%$ & $29 a$ & $12.0 \%$ & $6.2 \%$ & 241 & $6.6 \%$ & $126_{a}$ & $52.3 \%$ & $6.8 \%$ & $115_{a}$ & $47.7 \%$ & $6.4 \%$ & 241 & $6.6 \%$ \\
\hline & $46-59$ & $802 a$ & $87.5 \%$ & $25.2 \%$ & $115_{a}$ & $12.5 \%$ & $24.6 \%$ & 917 & $25.1 \%$ & $486 a$ & $53.0 \%$ & $26.1 \%$ & $431 \mathrm{a}$ & $47.0 \%$ & $24.1 \%$ & 917 & $25.1 \%$ \\
\hline & $60-74$ & $1344_{a}$ & $87.7 \%$ & $42.2 \%$ & $189_{a}$ & $12.3 \%$ & $40.5 \%$ & 1533 & $42.0 \%$ & $795 a$ & $51.9 \%$ & $42.7 \%$ & $738 \mathrm{a}$ & $48.1 \%$ & $41.2 \%$ & 1533 & $42.0 \%$ \\
\hline & 75 - more & $797 \mathrm{a}$ & $85.7 \%$ & $25.0 \%$ & $133_{a}$ & $14.3 \%$ & $28.5 \%$ & 930 & $25.5 \%$ & $438 \mathrm{a}$ & $47.1 \%$ & $23.5 \%$ & $492_{b}$ & $52.9 \%$ & $27.5 \%$ & 930 & $25.5 \%$ \\
\hline & Total & 3187 & $87.2 \%$ & $100.0 \%$ & 467 & $12.8 \%$ & $100.0 \%$ & 3654 & $100.0 \%$ & 1863 & $51.0 \%$ & $100.0 \%$ & 1791 & $49.0 \%$ & $100.0 \%$ & 3654 & $100.0 \%$ \\
\hline \multirow{4}{*}{$\frac{0}{\text { के }}$} & Left & $1459 a$ & $88.8 \%$ & $50.1 \%$ & $184 \mathrm{a}$ & $11.2 \%$ & $46.7 \%$ & 1643 & $49.7 \%$ & $832 a$ & $50.6 \%$ & $49.1 \%$ & $811_{a}$ & $49.4 \%$ & $50.3 \%$ & 1643 & $49.7 \%$ \\
\hline & Right & $1440_{a}$ & $87.6 \%$ & $49.5 \%$ & $204_{a}$ & $12.4 \%$ & $51.8 \%$ & 1644 & $49.7 \%$ & $852 a$ & $51.8 \%$ & $50.3 \%$ & $792 a$ & $48.2 \%$ & $49.1 \%$ & 1644 & $49.7 \%$ \\
\hline & Bilateral & $12 \mathrm{a}$ & $66.7 \%$ & $0.4 \%$ & $6 \mathrm{~b}$ & $33.3 \%$ & $1.5 \%$ & 18 & $0.5 \%$ & $9 \mathrm{a}$ & $50.0 \%$ & $0.5 \%$ & $9 \mathrm{a}$ & $50.0 \%$ & $0.6 \%$ & 18 & $0.5 \%$ \\
\hline & Total & 2911 & $88.1 \%$ & $100.0 \%$ & 394 & $11.9 \%$ & $100.0 \%$ & 3305 & $100.0 \%$ & 1693 & $51.2 \%$ & $100.0 \%$ & 1612 & $48.8 \%$ & $100.0 \%$ & 3305 & $100.0 \%$ \\
\hline \multirow{7}{*}{ 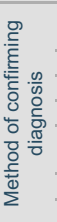 } & $\begin{array}{l}\text { Clinical without } \\
\text { specification }\end{array}$ & $352 a$ & $93.1 \%$ & $11.0 \%$ & $26_{b}$ & $6.9 \%$ & $5.6 \%$ & 378 & $10.3 \%$ & $189_{a}$ & $50.0 \%$ & $10.1 \%$ & $189_{a}$ & $50.0 \%$ & $10.6 \%$ & 378 & $10.3 \%$ \\
\hline & Clinical diagnosis & $313_{a}$ & $94.6 \%$ & $9.8 \%$ & $18_{b}$ & $5.4 \%$ & $3.9 \%$ & 331 & $9.1 \%$ & $162 \mathrm{a}$ & $48.9 \%$ & $8.7 \%$ & $169_{a}$ & $51.1 \%$ & $9.4 \%$ & 331 & $9.1 \%$ \\
\hline & Cytology & $14 a$ & $82.4 \%$ & $0.4 \%$ & $3 a$ & $17.6 \%$ & $0.6 \%$ & 17 & $0.5 \%$ & $13 a$ & $76.5 \%$ & $0.7 \%$ & $4 b$ & $23.5 \%$ & $0.2 \%$ & 17 & $0.5 \%$ \\
\hline & Histology of Metastasis & $14 a$ & $100.0 \%$ & $0.4 \%$ & & & & 14 & $0.4 \%$ & $6 a_{a}$ & $42.9 \%$ & $0.3 \%$ & $8 \mathrm{a}$ & $57.1 \%$ & $0.4 \%$ & 14 & $0.4 \%$ \\
\hline & $\begin{array}{l}\text { Histology of Primary } \\
\text { Tumor }\end{array}$ & $2473 a$ & $85.5 \%$ & $77.6 \%$ & $420_{b}$ & $14.5 \%$ & $89.9 \%$ & 2893 & $79.2 \%$ & $1480_{a}$ & $51.2 \%$ & $79.4 \%$ & $1413_{a}$ & $48.8 \%$ & $78.9 \%$ & 2893 & $79.2 \%$ \\
\hline & Others & $21 a$ & $100.0 \%$ & $0.7 \%$ & & & & 21 & $0.6 \%$ & $13_{a}$ & $61.9 \%$ & $0.7 \%$ & $8 a$ & $38.1 \%$ & $0.4 \%$ & 21 & $0.6 \%$ \\
\hline & Total & 3187 & $87.2 \%$ & $100.0 \%$ & 467 & $12.8 \%$ & $100.0 \%$ & 3654 & $100.0 \%$ & 1863 & $51.0 \%$ & $100.0 \%$ & 1791 & $49.0 \%$ & $100.0 \%$ & 3654 & $100.0 \%$ \\
\hline
\end{tabular}



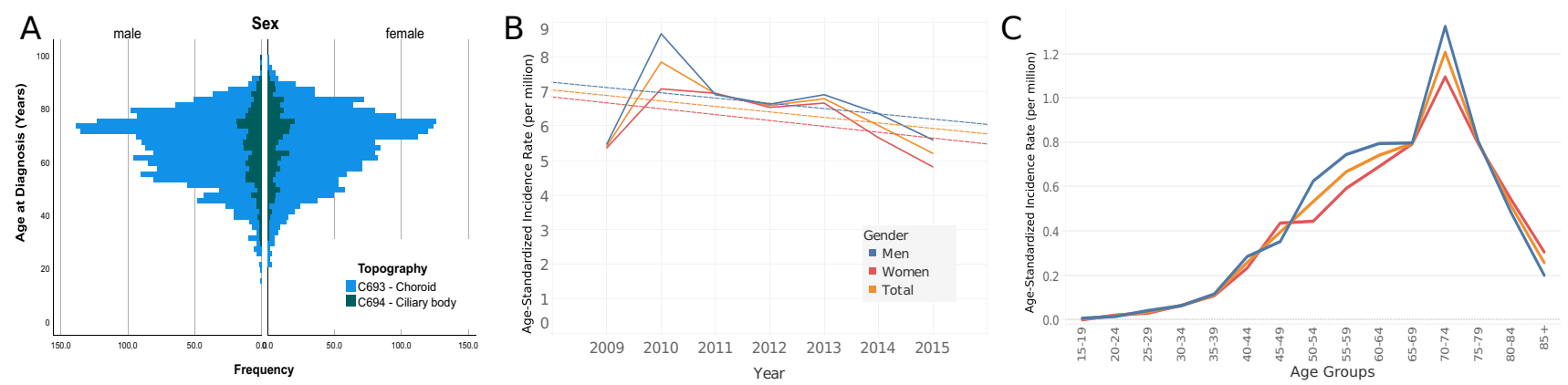

Fig. 1 Distribution of patients. Age at diagnosis by topography by sex (A), age-standardized incidence rate per year (B), crude incidence rate (C), age-standardized incidence rate (D)

\section{Survival}

The 5-year cumulative overall survival rate stood at $47 \%$, compared with an $84 \%$ cancer-specific survival rate. Women showed better overall survival compared with men (50\% vs $45 \%, p$-value $<0.001)$. Similarly, patients with choroidal melanomas showed better overall survival compared to those diagnosed with ciliary body melanomas (49\% vs $37 \%$, $p$-value $<0.001)$. Furthermore, women showed significantly better cancer-specific survival (85\% compared with $82 \%$ in men, $p=0.03$ ). Patients with choroidal melanomas showed a slightly better survival compared with those with ciliary body and iris $(84 \%$ vs $80 \%, p$-value $=0.168)($ Fig. 3, Supplementary Figs. 1 and 2).

\section{Multivariate Cox regression}

In our model, women $(p=0.001)$, younger age patients $(p<0.001)$, patients from Berlin $(p=0.001)$, and patients with choroidal tumors $(p<0.001)$ showed significantly higher overall survivals. In the cancer-specific survival model, those from Berlin $(p<0.001)$ showed significantly better survival (Supplementary Figs. 1 and 2).

\section{Discussion}

Melanoma is the most common primary intraocular malignancy in adults, but it may affect orbital tissues at lower rates. Singh et al. reported the incidence in the USA to

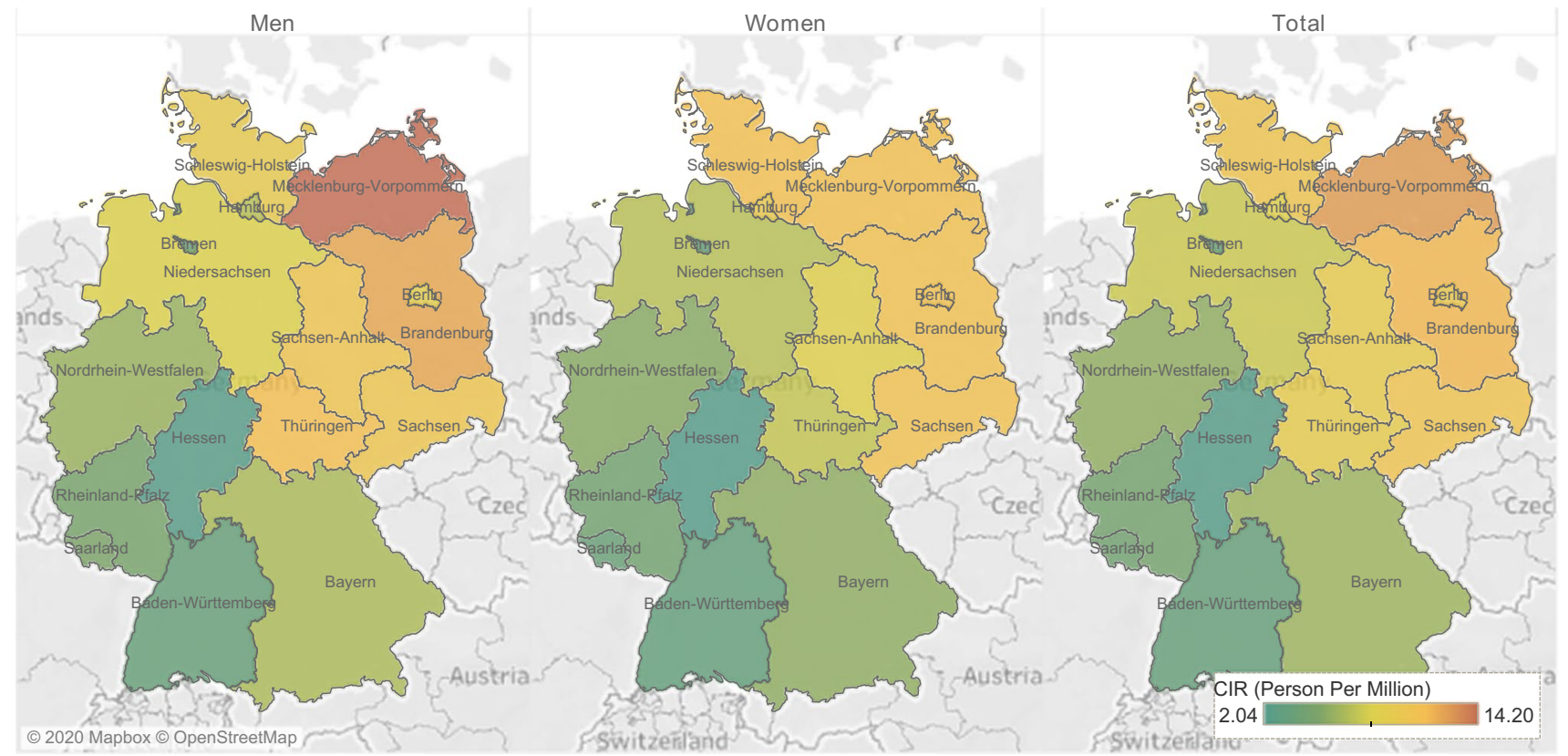

Fig. 2 Crude incidence rates by state 
Table 2 Stage of the disease

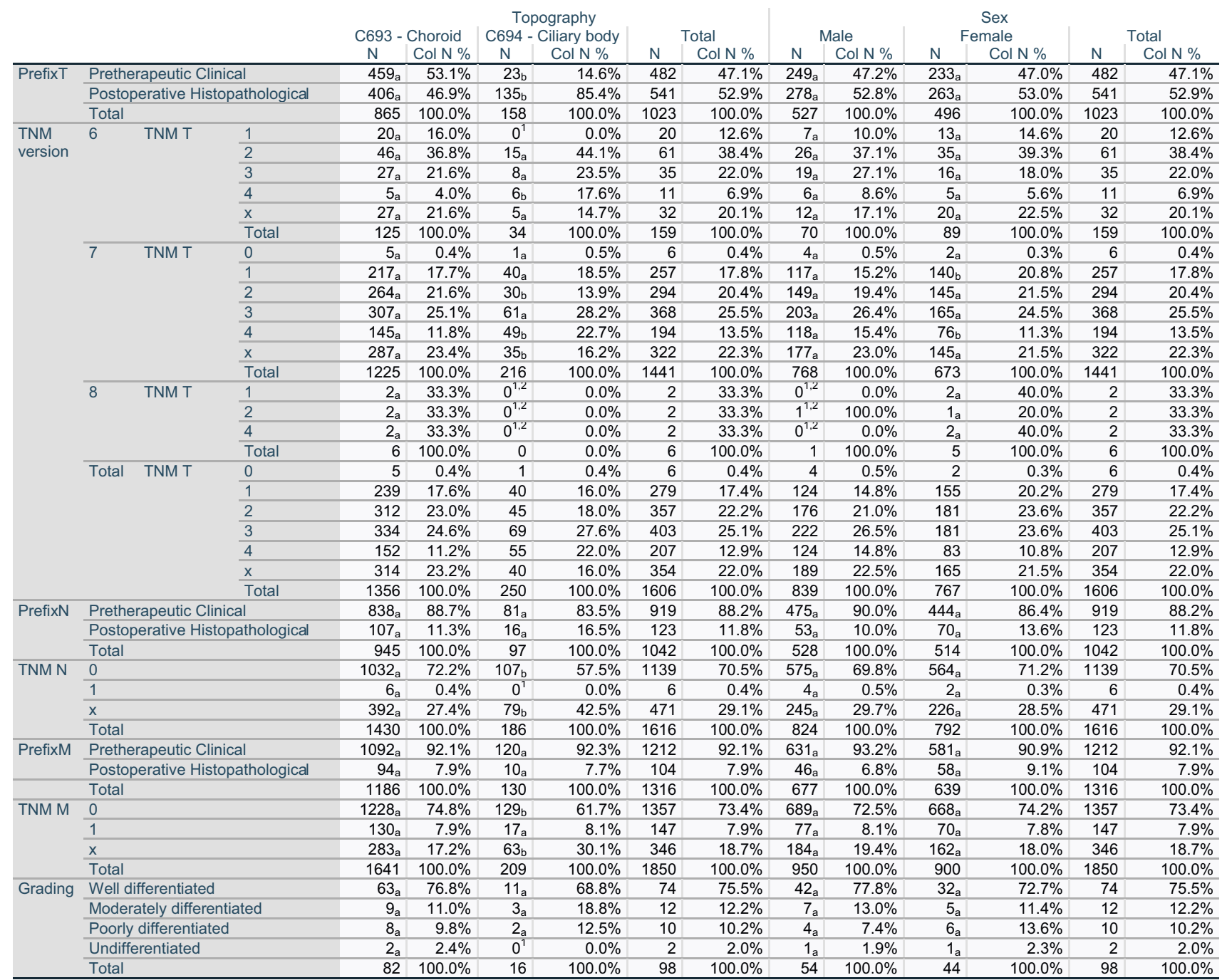

Note: Values in the same row and subtable not sharing the same subscript are significantly different at $p<.05$ in the two-sided test of equality for column proportions. Cells with no subscript are not included in the test. Tests assume equal variances.

1. This category is not used in comparisons because its column proportion is equal to zero or one.

2. This category is not used in comparisons because the sum of case weights is less than two.

3. Tests are adjusted for all pairwise comparisons within a row of each innermost subtable using the Bonferroni correction.

have stood at 5.1 per million [2]. This reported value nearly matched our findings with regard to central Germany. The age-specific incidence in the US population increased by age to reach a peak incidence in females at between 65 and 69 year of age and males at between 70 and 74 years of age. The previously mentioned US Surveillance, Epidemiology, and End Results Program "SEER" study showed a lower relative incidence of the disease among African Americans and Asian Americans. Unfortunately, the German national registry does not specify the ethnicity of patients. It would be worthwhile to conduct a study that examines ethnic variations of uveal melanomas, given the recent flow of refugees from both the Middle and Far East regions [20].

A study that included data from European cancer registries between 1983 and 1994, including Saarland (a German state, as aforementioned), reported incidence rates ranging from $<2$ per million in southern Spain and Italy to $>8$ in Norway and Denmark in the north, respectively [4]. Our study showed a similar distribution within the mentioned range but within the same country. The observed higher incidences in northern and eastern Germany compared with the southern and western regions of the country may be attributable to ethnic variations, with movement of populations with pigmented or less fair skin over generations from western and southern Europe on the one hand, and similar ethnic make-up in northern states as that of Nordic countries. Fair skin was associated with an increased incidence of uveal melanoma, possibly due to unusual exposure to sunlight [21]. However, the relationship to sunlight exposure is contradictory in literature [6, 22]. In this study, patterns of 
A Overall Survival
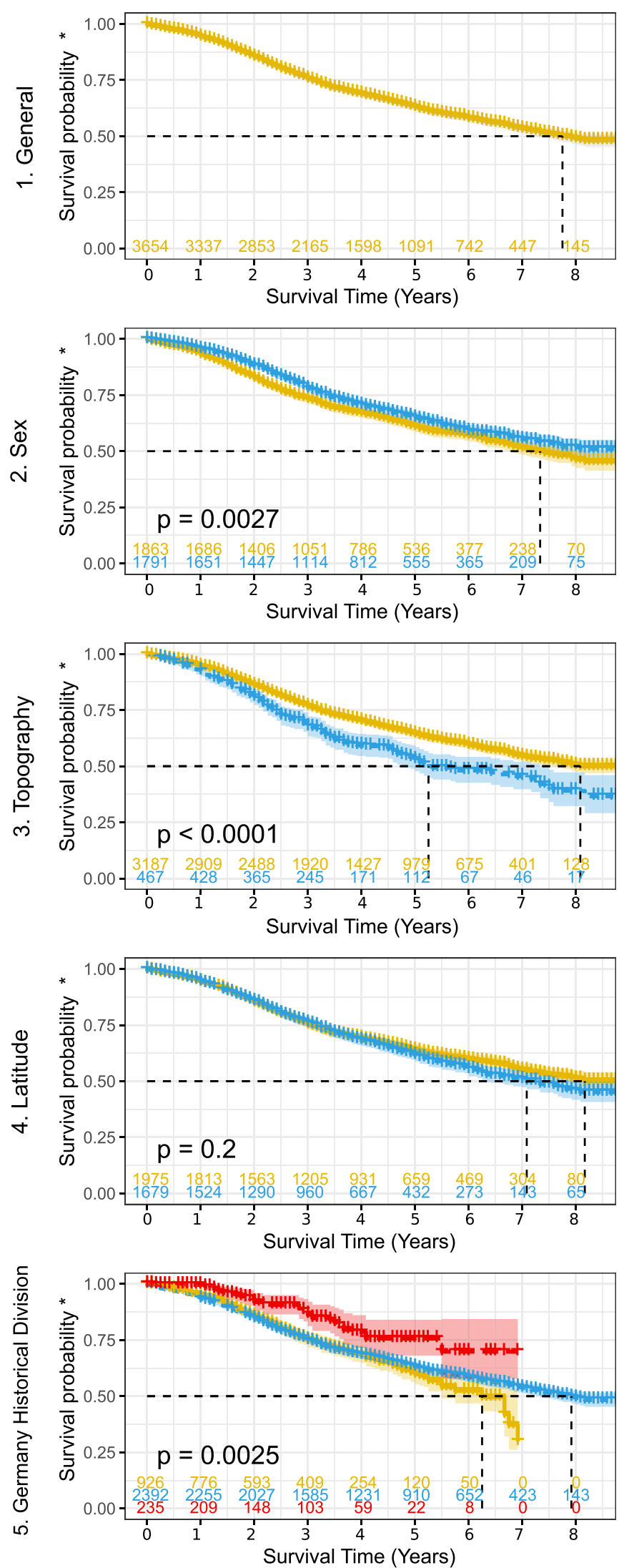

${ }^{*}$ cumulative proportion (of surviving)
B Cancer-Specific Survival
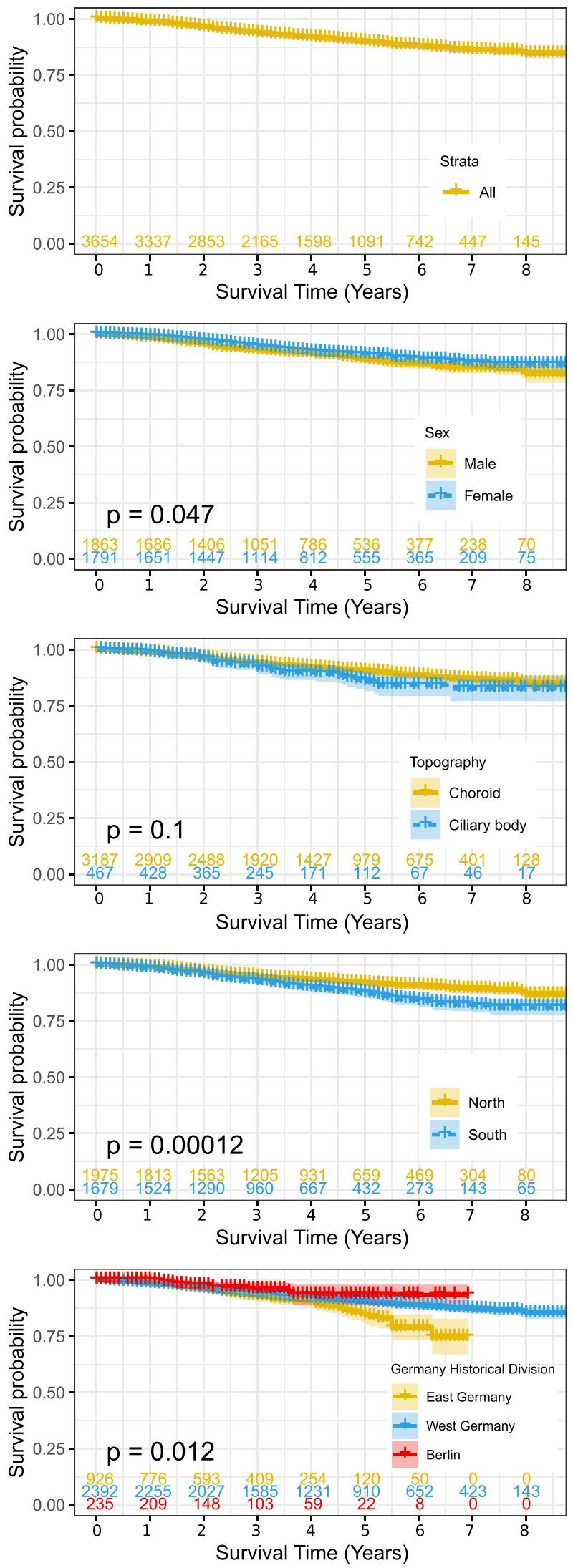
4Fig. 3 Overall and cancer-specific survival (A and B), by gender (2), topography (3), latitude (4), and Germany old segmentation scheme (5)

distribution of uveal melanoma were illustrated in maps, rather than point gradients, due to the fact that some German states extend over longitudes.

The highest reported population-based incidence worldwide was of Australian men. It stood at a rate of 10.9 per million, while the lowest population-based incidence was reported in Japan with 0.3 per million [23]. The mentioned high rate in Australia is may be attributable to its majority susceptible Caucasian White population of European origins. A previous study used two different methods to calculate incidences of uveal melanoma by integrating data from the population registry of Münster, a city in the federal state of Northrhine-Westphalia, with data from two case-controlled studies in that region. Two estimates, 2.3 and 8.6 per million, were reported [24]. We calculated an incidence of 5.7 per million for the same state, which is close to the mean of the previously mentioned two estimates from the earlier study. The earlier study by Virgili et al. also reported an incidence of 4.5 per million in the state of Saarland, approximating the incidence rate reported for the same state by our study (4.3 per million) [4].

Contrary to the increasing incidence of skin melanoma in the USA and other countries, uveal melanoma has shown varying annual incidence trends. For example, while Sweden has experienced a declining incidence of uveal melanoma over the years [22], Canada has had a small annual increase in incidence over time [25]. Our study has found a slight decline in incidence over time, a finding similar to that from north European countries. Our study showed varying incidence trends in each German state as well. We believe that further follow-up studies are vital for a better understanding of long-term trends.

Older age at diagnosis as well as diagnoses of ciliary body tumors was associated with worse overall survival. Previous studies have reported increased incidences of uveal melanomas as well as worse prognoses in older age groups $[26,27]$. The better survival in younger age groups was attributed to the underlying histological features of uveal melanomas commonly associated with younger age. Other factors that may have influenced measured incidence rates may include social and psychological factors that drove certain patients to seek diagnosis and treatment. Furthermore, specific mutations, such as the SF3B1 mutation, were found to be associated with younger age, choroidal involvement, and a better prognosis[28]. On the other hand, BAP1 mutations were found to be associated with older age and worse prognosis. Notably, the lower survival rate of patients with ciliary body melanomas was found to be an independent prognostic factor for survival in a number of studies [26, 29, 30]. However, in our study, the cancer-specific survival was not significantly attributable to topography. This lower survival in the other studies was attributed to its higher rate of metastasis [31]. Risk of metastasis in these cases was reportedly related to tumor size, microvascular patterns, and monosomy 3 and $8 \mathrm{q}$ gain [32],

Better survival rates for women were a notable finding of our study. This, as a number of studies have suggested, could be attributed to women's hormonal profile, varied genetic predispositions compared with men, and/or differences in occupational factors including amount of sun exposure [21, 33-35]. Other studies have attributed the differences to a tendency towards tumor extension, or to the involvement of ciliary body extensions [36]. We believe that those clinical aspects should be considered in parallel with the relevant molecular, genetic, and environmental backgrounds of each patient.

In general, the survival of patients from Berlin showed both higher overall and cancer-specific survivals, while those from both eastern and westerns states of Germany showed similar 5-year overall and cancer-specific survivals. On the other hand, graphs showed lower overall survivals after the period of 5 years, indicating a possible affection of health status on the long term, the effect of the age distribution between eastern and western states, or other factors that were not considered in this study. However, our analysis did not yield any differences in the distribution of uveal melanomas between different regions of Germany by age.

Most of the patients in our study were reported to have been diagnosed with the non-specified 8720/3 malignant melanoma histological subtype. This may give an impression that pathological studies were either not carefully done or were erroneously reported by the registrars. On the contrary, this highlights the dependency on clinical diagnosis for the management of uveal melanomas, currently the cornerstone of the diagnosis of these tumors [37]. Clinical diagnosis has been reported to have had an accuracy of up to $99 \%$ [38]. This is clear for medium-sized to large melanomas, but small ones are often hard to diagnose. Moreover, this unspecified histological coding can be attributed to the success of clinical management, resulting in the unavailability of pathological samples. On the other hand, some authors have proposed that this was related to the increasing complexity of incidence calculation [39].

The low DCO (not presented) rate indicates a relatively high level of reliable data that can be used in further research. Both show the accuracy of the reporting system in the deliverance of accurate information at presentation or during management, allowing a chance for further follow-up. On the other hand, the discrepancy between the method of confirming diagnoses and histopathological staging indicates a gap in the reporting of 
the histopathological staging of uveal melanomas. Establishing a central cancer registry for uveal melanomas can help more accurately complementing the national general cancer registry.

This study is the first to report on the nationwide incidence of uveal melanomas in Germany. As with all registry-based studies, it has limitations. Some differences between states can be attributed to the degree of registry completion. Two of the southern registries (Hessen and Baden-Wuerttemberg) were founded in 2007-2009 and, therefore, are still being built up. Moreover, variations in the details reported by registries, including treatment and outcome, could have resulted from a lag time between diagnoses and reporting times. Furthermore, the small number of patients within some groups and states may result in inaccurate subgroup and trend analyses. Further efforts should be invested in follow-up studies and training ophthalmologists and cancer registrars on reporting uveal melanomas and other cancers as well.

In conclusion, the age-standardized incidence of uveal melanoma in Germany was 6.41 per million. Men showed higher standardized incidences and lower survivals than women. Patients with choroidal disease showed higher survivals than those with a ciliary body or iridial tumors. Patients from the former East Germany showed similar 5-year survival rates to those from the former West Germany.

Supplementary Information The online version contains supplementary material available at https://doi.org/10.1007/s00417-021-05317-7.

Acknowledgements The authors would like to thank Dr. Klaus Kraywinkel for the efforts in extracting the data and Mr. Mohamed-Ismail Rakha for the language revision.

Author contribution ASA: Conceptualization, methodology, visualization, investigation, data analysis, resources, writing-original draft. AS: Conceptualization, writing-original draft. PW: Interpretation, writingfinal. MR: Interpretation, writing-final, supervision.

Funding Open Access funding enabled and organized by Projekt DEAL.

Availability of data and material Not applicable.

Code availability Not applicable.

\section{Declarations}

Ethics approval The study is waived from ethical committee approval due to the anonymity of patients' data used and considered non-human subject research. The studies involving human participants were conducted in accordance with the ethical standards of the institutional and/ or national research committee and with the 1964 Helsinki Declaration and its later amendments or comparable ethical standards. Cancer data is anonymized, reportable by law and considered non-human subject research. Thus, it is IRB approval and HIPAA-exempted.
Conflict of interest The authors declare no competing interests.

Open Access This article is licensed under a Creative Commons Attribution 4.0 International License, which permits use, sharing, adaptation, distribution and reproduction in any medium or format, as long as you give appropriate credit to the original author(s) and the source, provide a link to the Creative Commons licence, and indicate if changes were made. The images or other third party material in this article are included in the article's Creative Commons licence, unless indicated otherwise in a credit line to the material. If material is not included in the article's Creative Commons licence and your intended use is not permitted by statutory regulation or exceeds the permitted use, you will need to obtain permission directly from the copyright holder. To view a copy of this licence, visit http://creativecommons.org/licenses/by/4.0/.

\section{References}

1. Yonekawa Y, Kim IK (2012) Epidemiology and management of uveal melanoma. Hematol Oncol Clin N Am 26:1169-1184. https://doi.org/10.1016/j.hoc.2012.08.004

2. Singh AD, Turell ME, Topham AK (2011) Uveal melanoma: trends in incidence, treatment, and survival. Ophthalmology 118:1881-1885. https://doi.org/10.1016/j.ophtha.2011.01.040

3. Al-Jamal RT, Cassoux N, Desjardins L et al (2016) The pediatric choroidal and ciliary body melanoma study: a survey by the European Ophthalmic Oncology Group. Ophthalmology 123:898-907. https://doi.org/10.1016/j.ophtha.2015.12.024

4. Virgili G, Gatta G, Ciccolallo L et al (2007) Incidence of uveal melanoma in Europe. Ophthalmology 114:2309-2315.e2. https:// doi.org/10.1016/j.ophtha.2007.01.032

5. Aronow ME, Topham AK, Singh AD (2018) Uveal melanoma: 5-year update on incidence, treatment, and survival (SEER 19732013). Ocul Oncol Pathol 4:145-151. https://doi.org/10.1159/ 000480640

6. Yu G-P, Hu D-N, McCormick SA (2006) Latitude and incidence of ocular melanoma. Photochem Photobiol 82:1621-1626. https:// doi.org/10.1562/2006-07-17-RA-970

7. Nolte E, McKee M (2004) Changing health inequalities in east and west Germany since unification. Soc Sci Med 58:119-136. https://doi.org/10.1016/S0277-9536(03)00153-9

8. Mielck A (2000) Comparison of health inequalities between East and West Germany. Eur J Public Health 10:262-267. https://doi. org/10.1093/eurpub/10.4.262

9. Kraywinkel K, Kötschau A (2020) Center for Cancer Registry Data (ZfKD) in the Robert Koch Institute: population-based cancer registry dataset from the German Center for Cancer Registry Data

10. Wolf U, Barnes B, Bertz J et al (2011) The (German) Center for Cancer Registry Data (ZfKD) at the Robert Koch Institute (RKI) in Berlin. Bundesgesundheitsb Gesundheitsforsch Gesundheitsschutz 54:1229-1234. https://doi.org/10.1007/s00103-011-1361-7

11. Sobin LH, Gospodarowicz MK, Wittekind C (2011) Malignant melanoma of uvea. In: TNM Classification of Malignant Tumours, 7th ed. Wiley, pp 284-290

12. Statistisches Bundesamt "Fedral office of Statistics." https://www. destatis.de. Accessed 2 Nov 2020

13. Haberland J, Bertz J, Wolf U et al (2010) German cancer statistics 2004. BMC Cancer 10:52. https://doi.org/10.1186/ 1471-2407-10-52

14. IBM Corp (2020) IBM SPSS Statistics for Windows, Version 27.0. https://www.ibm.com/products/spss-statistics. Accessed 8 Aug 2020 
15. Microsoft Corp. (2021) Microsoft Excel. Version 16.0.13801.20360. https://www.microsoft.com/en-us/microsoft365/excel. Accessed 3 Apr 2021

16. Tableau-Software (2020) Tableau Desktop Version 2020.1.2. https://www.tableau.com/. Accessed 11 Oct 2020

17. Breslow NE, Day NE (1987) Statistical methods in cancer research. Volume II--The design and analysis of cohort studies. IARC Sci Publ 1-406

18. Armitage P, Berry G (1994) Statistical methods in medical research, 3rd edn. Boston, Oxford

19. Kim HJ, Fay MP, Feuer EJ, Midthune DN (2000) Permutation tests for joinpoint regression with applications to cancer rates. Stat Med 19:335-351. https://doi.org/10.1002/(sici)1097-0258(20000 215) 19:3\%3c335::aid-sim336\%3e3.0.co;2-z

20. Eurostat (2016) Asylum and first time asylum applicants by citizenship, age and sex Annual aggregated data (rounded). In: Eurostat - Data Explor. http://appsso.eurostat.ec.europa.eu/nui/show. do?dataset=migr_asyappctza\&lang=en. Accessed 5 Oct 2016

21 Singh AD, Rennie IG, Seregard S et al (2004) Sunlight exposure and pathogenesis of uveal melanoma. Surv Ophthalmol 49:419 28. https://doi.org/10.1016/j.survophthal.2004.04.009

22. Moan J, Cicarma E, Setlow R et al (2010) Time trends and latitude dependence of uveal and cutaneous malignant melanoma induced by solar radiation. Dermatoendocrinology 2:3-8. https://doi.org/ 10.4161/derm.2.1.11745

23. Kaneko A (1999) Japanese contributions to ocular oncology. Int J Clin Oncol 4:321-326. https://doi.org/10.1007/s101470050078

24. Stang A, Schmidt-Pokrzywniak A, Lehnert M et al (2006) Population-based incidence estimates of uveal melanoma in Germany. Supplementing cancer registry data by case-control data. Eur $\mathbf{J}$ Cancer Prev 15:165-170. https://doi.org/10.1097/01.cej.00001 97453.79733.a6

25. Ghazawi FM, Darwich R, Le M et al (2019) Uveal melanoma incidence trends in Canada: a national comprehensive populationbased study. Br J Ophthalmol. https://doi.org/10.1136/bjophthalm ol-2018-312966

26. Seddon JM, Albert DM, Robinson N, Lavin PT (1983) A Prognostic factor study of disease-free interval and survival following enucleation for uveal melanoma. Arch Ophthalmol 101:1894-1899. https://doi.org/10.1001/archopht.1983.01040020896012

27. Damato BE, Heimann H, Kalirai H, Coupland SE (2014) Age, survival predictors, and metastatic death in patients with choroidal melanoma: tentative evidence of a therapeutic effect on survival. JAMA Ophthalmol 132:605-613. https://doi.org/10.1001/jamao phthalmol.2014.77

28. Decatur CL, Ong E, Garg N et al (2016) Driver mutations in uveal melanoma. JAMA Ophthalmol 134:728. https://doi.org/10.1001/ jamaophthalmol.2016.0903
29. Augsburger JJ, Gamel JW (1990) Clinical prognostic factors in patients with posterior uveal malignant melanoma. Cancer 66:1596-1600. https://doi.org/10.1002/1097-0142(19901001) 66:7\%3c1596::aid-cncr2820660726\%3e3.0.co;2-6

30. Rummelt V, Folberg R, Woolson RF et al (1995) Relation between the microcirculation architecture and the aggressive behavior of ciliary body melanomas. Ophthalmology 102:844-851. https:// doi.org/10.1016/s0161-6420(95)30947-5

31. Shields CL, Furuta M, Thangappan A et al (2009) Metastasis of uveal melanoma millimeter-by-millimeter in 8033 consecutive eyes. Arch Ophthalmol (Chicago, Ill 1960) 127:989-98. https:// doi.org/10.1001/archophthalmol.2009.208

32. Li W, Gragoudas ES, Egan KM (2000) Metastatic melanoma death rates by anatomic site after proton beam irradiation for uveal melanoma. Arch Ophthalmol (Chicago, Ill 1960) 118:1066-70. https://doi.org/10.1001/archopht.118.8.1066

33. Holly EA, Aston DA, Ahn DK et al (1991) Uveal melanoma, hormonal and reproductive factors in women. Cancer Res 51:1370-1372

34. Schmidt-Pokrzywniak A, Jöckel K-H, Bornfeld N et al (2009) Positive interaction between light iris color and ultraviolet radiation in relation to the risk of uveal melanoma: a case-control study. Ophthalmology 116:340-348. https://doi.org/10.1016/j.ophtha. 2008.09.040

35. Karagas MR, Zens MS, Stukel TA et al (2006) Pregnancy history and incidence of melanoma in women: a pooled analysis. Cancer Causes Control 17:11-19. https://doi.org/10.1007/ s10552-005-0281-y

36. Damato BE, Coupland SE (2012) Differences in uveal melanomas between men and women from the British Isles. Eye (Lond) 26:292-299. https://doi.org/10.1038/eye.2011.272

37. Damato EM, Damato BE (2012) Detection and time to treatment of uveal melanoma in the United Kingdom: an evaluation of 2,384 patients. Ophthalmology 119:1582-1589. https://doi.org/ 10.1016/j.ophtha.2012.01.048

38. Vine A, Sneed S, Elner V et al (1990) Accuracy of diagnosis of choroidal melanomas in the collaborative ocular melanoma study. Arch Ophthalmol 108:1268. https://doi.org/10.1001/archo pht.1990.01070110084030

39. Stang A, Parkin DM, Ferlay J, Jöckel K-H (2005) International uveal melanoma incidence trends in view of a decreasing proportion of morphological verification. Int J Cancer 114:114-123. https://doi.org/10.1002/ijc.20690

Publisher's note Springer Nature remains neutral with regard to jurisdictional claims in published maps and institutional affiliations. Presentation Parts of this publication were presented at the German Ophthalmological Society meeting 2020.

\section{Authors and Affiliations}

\section{Ahmad Samir Alfaar ${ }^{1,2}\left(\mathbb{D} \cdot\right.$ Anas Saad $^{3}(1) \cdot$ Peter Wiedemann $^{1} \cdot$ Matus Rehak $^{1}$}

1 Department of Ophthalmology, University Hospital Leipzig, University of Leipzig, Liebigstr. 10-14, 04103 Leipzig, Germany

2 Experimental Ophthalmology, Charité-Universitätsmedizin Berlin, Berlin, Germany
3 Heart and Vascular Institute, Cleveland Clinic Foundation, Cleveland, $\mathrm{OH}$, USA 